\title{
Agriculture and food
}

\section{Yoseph Araya*, Andrew Dorward ${ }^{\dagger}$, Jasmine Gideon*, Richard Kock ${ }^{\ddagger}$, Laurence Smith ${ }^{\S}$ and Jeff Waage}

${ }^{\star}$ Birkbeck College, Department of Geography, Environment and Development Studies, 'School of Oriental and African Studies, Centre for Environment, Development and Policy, ${ }^{\star}$ Birkbeck College, Department of Geography, Environment and Development Studies, ₹Royal Veterinary College, Department of Pathology and Pathogen Biology, ${ }^{s}$ School of Oriental and African Studies, Centre for Development, Environment and Policy, 'London International Development Centre; School of Oriental and African Studies, Centre for Development, Environment and Policy

\section{What is the historical process by which goal setting in this sector has developed?}

Over the past two decades, there has been little development in goal setting directed specifically at targets and indicators for agriculture and food outcomes. This reflects the limited attention given by the international development community to agriculture in the late 1990s and early 2000s. The FAO's 2002 World Food Summit, which aimed to boost the disappointing progress made five years after the 1996 Summit, reiterated the earlier pledge to reduce the number of hungry people to 400 million by 2015. African Heads of Government did, however, agree to allocate 10 per cent of their national budgets to agriculture in the 2003 Maputo Declaration. Since the publication of the World Development Report 2008: Agriculture for Development and the 2008 global food price spike, a renewed interest in agriculture has led to generally unfulfilled budgetary and spending commitments (e.g. the 2009 G8

How to cite this book chapter:

Araya, Y, Dorward, A, Gideon, J, Kock, R, Smith, L, and Waage, J. 2015. Agriculture and food. In: Waage, J and Yap, C. (eds.) Thinking Beyond Sectors for Sustainable Development. Pp. 45-50. London: Ubiquity Press. DOI: http://dx.doi.org/ 10.5334/bao.f 
'LAquila' Joint Statement on Global Food Security and subsequent G8 meetings), however, to date no achievement targets have been agreed.

Agriculture and food-related outcomes were embedded in MDG 1(Eradicate Extreme poverty and hunger), which included hunger targets (Target 1C, 'Halve, between 1990 and 2015, the proportion of people who suffer from hunger') and indicators (1.8, 'Prevalence of underweight children under-five years of age', and 1.9, 'Proportion of population below minimum level of dietary energy consumption'). The MDG 1.9 indicator was based on the 1996 World Food Summit goal of reducing the number of people suffering from hunger by half by 2015 . The process of deciding these targets involved different constituencies engaged with the two different indicators.

UNICEF, the WHO, and a range of governments and other agencies have been responsible for providing data on the prevalence of underweight children under five years of age (indicator 1.8) through surveys using, or compatible with, UNICEF's Multiple Indicator Cluster Survey (MICS), including the USAID-supported Demographic and Health Surveys programme. Although performance on this indicator is significantly related to food security (defined in terms of access to food, and its nutritional quality and utilisation), hunger itself (defined in terms of access to food) is more closely associated with indicator 1.9. FAO has published data on indicator 1.9, but there have been methodological and data difficulties that make it a poor measure of hunger or food insecurity. Concerns about this in the wake of the 2008 food price spike led to major methodological revisions by the FAO in 2012 (FAO, WFP \& IFAD 2012). While the new method has a number of improvements, there are still a number of concerns (for example the data is often poor and only looks at nutrition in terms of calories). There are also difficulties with indicator 1.8, as data is not available on an annual basis and stunting and wasting are better indicators of the separate effects of more chronic and acute undernutrition.

There has been little consideration of natural or wild food systems beyond consideration of their sustainability and governance, though some of these are locally and/or globally important for food security, most notably capture fisheries. Addressing potential negative effects of agriculture, including environmental degradation and the risk of food-related and zoonotic diseases, have also not figured directly in the development of goal setting.

\section{What progress has been achieved in this sector through the Millennium Development Goals and other processes?}

With regards to indicator 1.8 , the global target does not look like it will be met, with mixed achievements in different parts of Asia, non-achievement in Africa, and achievement in Latin America and the Caribbean.

With regards to indicator 1.9, a similar pattern is observed, with revised estimates showing that falls in the prevalence of undernourished people prior to 2007 
were not quite sufficient to be on track for meeting the MDG 1 target, and food price increases in 2008 and subsequent years further slowed down the rate of fall in incidence. However, with population growth in most poor and food insecure countries, absolute numbers of undernourished people have hardly fallen, meaning that the World Food Summit global target of halving the number of hungry people from that in 1990-92 by 2015 will be missed by a very wide margin.

As with other MDGs targets, there are wide variations between regions as regards to changes in prevalence and numbers of undernourished people. FAO, World Food Programme (WFP), and the International Fund for Agricultural Development (IFAD) (2013) estimates that absolute numbers of undernourished people have been falling in Asia, Latin America, and the Caribbean, with falls in prevalence on track to meet the MDGs target. In both West Asia and sub-Saharan Africa, however, absolute numbers of undernourished people have been rising, with some falls in prevalence in sub-Saharan Africa, but actual increases in prevalence in West Asia; although this is from a much lower 1990-92 starting point than that the other regions. Within Asia there has been a remarkable fall in prevalence in South East Asia, with a slightly lower but still remarkable fall in East Asia. However, South Asia achieved a lower fall in prevalence which, if continued, will not be enough to achieve the target. These reductions have, however, been achieved at considerable environmental cost and hence threats to their sustainability in the context of continuing economic and population growth. Fisheries management and stocks have fallen, though in some cases harvesting has been sustained by increases in fishing efforts. Zoonotic disease outbreaks and spread have increased.

\section{What is the current debate about future goal setting?}

Food and agriculture system debates are dominated by concerns about food security and sustainability. Food security is considered in terms of four pillars: availability, access and entitlements, utilisation, and stability. The goal-setting agenda tends to only explicitly consider the first two of these (sustainable food production and availability and access). Nutrition (which should encompass all four pillars) is often considered separately. Discussions of sustainable production, of access, and of nutrition all include issues of stability. However, whilst a variety of indicators (of varying quality) have been developed for measuring food availability, access, and utilisation, very few have been explicitly developed and applied to measure stability in any of these dimensions (Pangaribow, Gerber \& Torero 2013). Consequently, FAO, WFP, and IFAD (2013) and Pangaribow, Gerber \& Torero (2013) set out a wide range of potential indicators for the four pillars of food security, considering the relationships between the indicators and the pillars they describe, and the way that these change according to the scale of analysis (e.g. global, regional, national, sub-national groups, households, and individuals within households). 
Sustainability concerns tend to focus most attention on the sustainability of food production systems and therefore on food availability, revolving around the effects of population and economic growth on food demands (with economic growth leading to increased demand for more resource demanding livestock products), and resource loss and degradation (including the effects of climate change) depressing supply. Overall (global) supply capacities tend to be the focus of more technical agricultural debates.

Regional differences in supply and demand lead to considerations of regional food access, but there are also concerns about access for vulnerable groups (e.g. marginalised rural poor or deprived urban migrants, in terms of access and forced dietary change). Issues also arise around the nature of malnutrition, with important distinctions between undernutrition (shortage of calories), the increasing incidence of over-nutrition (leading to obesity and non-communicable diseases), and 'hidden hunger' from shortages of micronutrients, of which there are complex interactions between the three.

In the wider delineation the Open Working Group proposal Introduction and Proposed Goals and Targets on Sustainable Development for the Post-2015 Development Agenda highlights agriculture and food security, stressing its centrality to sustainable development. The key aspects are addressed in Goal 2 (End hunger, achieve food security and improved nutrition, and promote sustainable agriculture). Here, agriculture and food security are addressed in terms of food availability with brief mentions on food access, nutrition, and stability. However, there is no specific mention of the role of other relevant aspects in attaining agriculture and food security goals, such as gender equality (in Goal 5), healthy nutrition (in Goal 3), sustainable water/natural resource management (in Goals 6 and 15). As in the past, fisheries are considered largely in terms of conservation and governance (Goal 14), not as critical for local or global livelihoods and food systems, although rapid increases in aquaculture production are recognised.

In the 10 proposed Sustainable Development Solutions Network goals (Sustainable Development Solutions Network 2013a), Goal 6 explicitly focuses on increased agricultural productivity and rural prosperity, while Goal 1 focuses on ending poverty, including hunger and malnutrition. However, agriculture and food systems targets are seen as important for a large number of other goals, with a comprehensive discussion of these in Solutions for Sustainable Agriculture and Food Systems: technical report for the post-205 development agenda (Sustainable Development Solutions Network 2013b). This stresses the centrality of agriculture and food to other aspects of sustainable development, and argues for the pursuit of agricultural development through 'sustainable intensification', which aims to reduce the environmental footprint of agriculture while meeting all of its other goals.

A relatively new element of the debate on future agriculture and food goals relates to nutrition. While agricultural development has always had an implicit nutritional agenda relating to meeting human needs for energy, expectations 
on agriculture for nutrition are changing rapidly. An influential Lancet series in 2013 concluded that future nutrition-specific interventions for the poor (e.g. supplementary foods for mothers and infants) could not deliver all the improvements in nutrition (particularly micronutrients) required for healthy development, and that agriculture might play a larger role, e.g. through the increased availability and affordability of animal-based foods, pulses, vegetables, and fruit (Ruel, Alderman \& the Maternal and Child Nutrition Study Group 2013). Further, while undernutrition persists in low- and middleincome countries, obesity and other diet-related diseases are growing rapidly as well, and reflecting the same problem: that diets of the poor are dominated by foods high in calories and low in essential micronutrients. The establishment of a Global Panel on Agriculture and Food Systems for Nutrition in 2014 and launch of a Global Nutrition Report, which clearly indicates the important role of agriculture (IFPRI 2014), has stimulated an intense dialogue on how best to embed nutritional outcomes in the agriculture goals of the SDGs.

\section{References}

Food and Agriculture Organization of the United Nations (FAO), World Food Programme (WFP), \& International Fund for Agricultural Development (IFAD). (2012). The state of food insecurity in the world 2012. Economic growth is necessary but not sufficient to accelerate reduction of hunger and malnutrition. Rome: FAO.

Food and Agriculture Organization of the United Nations (FAO), World Food Programme (WFP), \& International Fund for Agricultural Development (IFAD). (2013). The state of food insecurity in the world 2013. The multiple dimensions of food insecurity. Rome: FAO.

International Food Policy Research Institute (IFPRI). (2014). Global nutrition report 2014: actions and accountability to accelerate the world's progress on nutrition. Washington DC: IFPRI.

Pangaribow, E., Gerber, N., \& Torero, M. (2013). Food and nutrition security indicators: a review. FOODSECURE working paper 5. The Hague: LEI Wageningen UR.

Ruel M., Alderman, H., \& the Maternal and Child Nutrition Study Group. (2013). Nutrition-sensitive interventions and programmes: how can they help to accelerate progress in improving maternal and child nutrition? Lancet, DOI: http://dx.doi.org/10.1016/S0140-6736(13)60843-0

Sustainable Development Solutions Network. (2013a). An action agenda for sustainable development: report for the UN secretary-general. New York: United Nations.

Sustainable Development Solutions Network. (2013b). Solutions for Sustainable Agriculture and Food Systems: technical report for the post-205 development agenda. New York: United Nations. 
50 Thinking Beyond Sectors for Sustainable Development

UN Open Working Group on Sustainable Development Goals (OWG SDG) (2015) Introduction and Proposed Goals and Targets on Sustainable Development for the Post2015 Development Agenda. Zero Draft. New York: United Nations. Retrieved from https://sustainabledevelopment.un.org/content/ documents/4523zerodraft.pdf 